\title{
Desain kuis pembelajaran fisika berbasis teknologi pada materi hukum gravitasi universal
}

\author{
Rian Priyadi \\ Pendidikan Fisika, Pascasarjana, Universitas Negeri Malang \\ Jl. Semarang 5, Malang \\ Surat-e: rianpriyadi94@gmail.com
}

\begin{abstract}
Penelitian ini bertujuan mengembangkan kuis pembelajaran fisika berbasis teknologi pada materi hukum gravitasi universal. Pengembangan kuis pembelajaran fisika menggunakan model 4-D. Hasil validasi menunjukkan bahwa media pembelajaran telah valid dan layak untuk diujicobakan. Berdasarkan hasil analisis dari persepsi responden $(\mathrm{N}=33)$, media yang dikembangkan sudah praktis dan bisa digunakan sebagai media belajar responden. Penelitian lanjutan diharapkan dapat menguji keefektifan penggunaan media pembelajaran berbasis teknologi yang telah dikembangkan dan mengembangkan media berbasis teknologi pada materi lainnya.
\end{abstract}

This study purpose to develop technology-based learning quiz in the universal gravity law topic. The Development of this quiz on physics learning using 4-D model. The validation results show that the learning media is valid and feasible to be tested. Based on results of analysis perceptions of respondents $(\mathrm{N}=33)$, obtained that the media developed is practical and can be used as a medium for student learning. Further research is expected to be able to test the effectiveness of the use of technology-based learning media that have been developed and develop technology-based media on other topic.

Kata kunci: media pembelajaran, teknologi, hukum gravitasi universal

\section{Pendahuluan}

ICT telah berkembang sangan pesat dalam dunia pendidikan. Penggunaan media berbasis ICT diharapkan dapat memberikan penjelasan yang lebih konkret terhadap sebuah konsep yang sedang dipelajari [1]. Berdasarkan hasil observasi pendahuluan, ditemui fakta masih minimnya ketersediaan media pembelajaran dan alat evaluasi pembelajaran yang diberikan oleh guru, sehingga siswa kurang mendapatkan penjelasan yang cukup dalam menyelesaikan masalah yang diberikan. Apabila masalah tersebut tidak teratasi, maka akan berdampak pada hasil belajar siswa. Masalah lain yang ditemukan yakni kurangnya penggunaan ICT dalam proses pembelajaran, sehingga siswa sulit memahami konsep yang sedang diajarkan karena terdapat konsep fisika yang bersifat abstrak.

Penelitian terdahulu telah mengembangkan media pembelajaran serupa, namun masih terdapat beberapa kelemahan. Hal ini dikarenakan media yang dikembangkan berfokus pada penyampaian bahan ajar tanpa berfokus memberikan umpan balik kepada pengguna media [2]. Selain itu, media pembelajaran yang telah dikembangkan kurang memperhatikan evaluasi yang diberikan kepada pengguna setelah mempelajari materi yang tersedia [3], [4].
Solusi yang dapat ditawarkan untuk memecahkan masalah tersebut adalah dengan mengembangkan media ajar fisika berupa kuis pembelajaran fisika berbasis teknologi. Penggunaan media pembelajaran dapat merangsang pikiran, perasaan, perhatian dan minat responden sehingga terjadi proses belajar [5], [6]. Dale [7] memperkirakan bahwa hasil belajar melalui indra pandang berkisar $75 \%$, indra dengar sekitar $13 \%$ dan indra lainnya berkisar $12 \%$.

Program komputer yang dapat digunakan untuk mengembangkan media pelajaran berbasis teknologi adalah Wondershare Quiz Creator. Pemilihan program ini didasari hasil media yang dibuat lebih Interface dan dapat dibuat secara offline. Sehingga dapat membantu dalam pembuatan media pembelajaran serta bisa disisipkan musik, animasi, gambar dan lainnya yang dapat menuntun responden dalam memahami konsep yang diajarkan.

Penelitian ini bertujuan untuk mengembangkan kuis pembelajaran fisik menggunakan program Wondershare Quiz Creator pada materi hukum gravitasi universal dan melihat persepsi siswa setelah menggunakan media pembelajaran berbasis teknologi. Manfaat dari penelitian ini adalah menghasilkan prototipe media pembelajaran berbasis teknologi pada materi hukum gravitasi universal. 
Makalah dipersiapkan dalam bentuk softcopy dengan format ukuran kertas A4. Batas tepi: atas $=2,54 \mathrm{~cm}$, bawah $=2,54 \mathrm{~cm}$, sisi $=1,9 \mathrm{~cm}$. Lebar kolom pada A4 adalah $8,6 \mathrm{~cm}$. Jarak antara dua kolom adalah $0,8 \mathrm{~cm}$. Ukuran paragraf menjorok adalah $0,35 \mathrm{~cm}$.

Tipe Ukuran dan Jenis huruf: ikuti ukuran yang telah dicantumkan dalam Tabel I. Untuk diperhatikan pada jenis ukuran, 1 point adalah sekitar $0,35 \mathrm{~mm}$. Ukuran huruf "j" kecil merupakan ukuran acuan. Jenis huruf lebih disarankan menggunakan Times New Roman.

Tiap kolom diatur rata kiri-kanan. Gunakan tabel dan gambar dengan penyesuaian terhadap panjang lebar kolom. Pada halaman terakhir makalah Anda, atur panjang lebarnya agar sama besar. Gunakan tanda hubung otomatis dan pemeriksa ejaan (bila tersedia).

Tiap kolom diatur rata kiri-kanan. Gunakan tabel dan gambar dengan penyesuaian terhadap panjang lebar kolom. Pada halaman terakhir makalah Anda, atur panjang lebarnya agar sama besar. Gunakan tanda hubung otomatis dan pemeriksa ejaan (bila tersedia).

Tiap kolom diatur rata kiri-kanan. Gunakan tabel dan gambar dengan penyesuaian terhadap panjang lebar kolom. Pada halaman terakhir makalah Anda, atur panjang lebarnya agar sama besar. Gunakan tanda hubung otomatis dan pemeriksa ejaan (bila tersedia).

\section{Metode Penelitian}

Jenis penelitian ini merupakan penelitian dan pengembangan (Research and Development). Langkahlangkah dalam pengembangan ini mengikuti desain 4-D oleh Tiagarajan et al (1974) yang terdiri dari empat langkah pengembangan seperti pada Gambar 1. Tahapan pengembangan pada penelitian ini dibatasi sampai pada tahap develop.

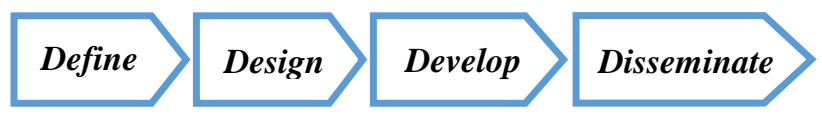

Gambar 1. Model Pengembangan 4D

Define, pada tahap ini dilakukan analisis kebutuhan. Hal-hal yang dianalisis ada mengecek ketersediaan bahan ajar di sekolah, analisis kurikulum dan observasi kegiatan pembelajaran yang dilakukan di dalam kelas.

Design, tahap awal yang dilakukan adalah menentukan tujuan pembelajaran yang akan digunakan, dan menentukan materi yang akan disampaikan. Langkah selanjutnya adalah membuat storyboard yang digunakan sebagai acuan proses pengembangan.

Develop, kuis pembelajaran fisika dikembangkan menggunakan program Wondershare Quiz Creator. Tampilan kuis pembelajaran fisika dibagi menjadi dua bagian. Pertama, kuis pembelajaran fisika pada hukum gravitasi universal. Kedua, pembahasan soal-soal kuis yang berguna untuk memberikan umpan balik kepada responden.

Karena adanya keterbatasan, pada pengembangan media pembelajaran berbasis teknologi ini hanya dibatasi sampai tahapan develop.

\section{Uji Coba Produk}

Setelah kuis pembelajaran fisika berbasis teknologi selesai dikembangkan, selanjutnya dilakukan uji coba pemakaian kepada responden $(N=33)$ untuk mengetahui persepsi responden terhadap kuis pembelajaran fisika berbasis teknologi yang dikembangkan.

\section{Instrumen Pengumpulan Data}

Instrumen pengumpulan data yang diguna-kan berupa kuesioner dengan menggunakan skala pengukuran Likert yang terdiri dari 13 butir pertanyaan yang dengan tiga aspek penilaian, yakni motivasi belajar, tampilan video, dan pemahaman materi. Skala Likert digunakan untuk mengukur persepsi dari responden [9]. Skala pengukuran terdiri dari lima skala secara rinci dijelaskan pada Tabel 1.

Tabel 1. Keterangan skala pengukuran

\begin{tabular}{cl}
\hline Skor & Keterangan \\
\hline 5 & Sangat setuju \\
4 & Setuju \\
3 & Ragu-ragu \\
2 & Tidak setuju \\
1 & Sangat tidak setuju \\
\hline
\end{tabular}

Aspek-aspek yang akan dinilai oleh responden pada proses pengembangan kuis pembelajaran fisika berbasis teknologi terdiri dari 13 pertanyaan, masing-masing pertanyaan responden diminta untuk memberikan penilaian sesuai dengan skala pada Tabel 1.

\section{Teknik Analisis Data}

Data yang diperoleh selanjutnya dilakukan analisis menggunakan persentase. Formula yang digunakan untuk menghitung persentase persepsi mengikuti perhitungan berikut:

$$
P=\frac{X_{i}}{X} \times 100 \%
$$

Keterangan:

$P \quad=$ Persentase dari hasil uji coba

$X_{i} \quad=$ Skor pada setiap indikator

$X=$ Skor maksimum

Berdasarkan hasil perhitungan, nilai rata-rata persentase yang didapatkan selanjutnya dikategorikan berdasarkan pada Tabel 2 .

Tabel 2. Kategori persentase persepsi responden

\begin{tabular}{lll}
\hline No & Interval $(\%)$ & Kriteria \\
\hline 1 & $80 \leq P \leq 100$ & Sangat Praktis \\
2 & $60 \leq P \leq 80$ & Praktis \\
3 & $40 \leq P \leq 60$ & Cukup Praktis \\
4 & $20 \leq P \leq 40$ & Kurang Praktis \\
5 & $00 \leq P \leq 20$ & Tidak Praktis \\
\hline
\end{tabular}

\section{Hasil Penelitian dan Pembahasan}

Hasil analisis kebutuhan menemukan perlunya media pembelajaran berbasis teknologi yang dapat membantu guru dalam memberikan materi pembelajaran tambahan. 
Keterbatasan waktu di sekolah memungkinkan agar siswa dapat menggunakan media tambahan yang dapat digunakan diluar jam pelajaran sekolah. Media pembelajaran yang dikembangkan merupakan kuis pembelajaran fisika berbasis teknologi, hal ini didasarkan bahwa media pembelajaran berbasis teknologi merupakan media berbasis audio-visual. Audio-visual merupakan sebuah media yang membutuhkan indra ganda dalam penggunaannya, [7] sehingga akan meningkatkan daya ingat responden [11].

Sebelum mendesain kuis pembelajaran fisika, terlebih dahulu menyiapkan storyboard. Rincian storyboard terlihat pada Tabel 3. Setelah semua kebutuhan telah disiapkan. Selanjutnya masuk kedalam proses pengembangan menggunakan program Wondershare Quiz Creator.

Tabel 3. Tampilan storyboard

\begin{tabular}{|c|c|c|c|c|}
\hline Bagian & \multicolumn{4}{|c|}{ Tampilan } \\
\hline \multirow{4}{*}{ Evaluasi 1} & \multicolumn{2}{|c|}{ Materi } & \multirow[b]{2}{*}{ Suara } & \multirow[b]{2}{*}{ Print } \\
\hline & & Info & & \\
\hline & \multicolumn{3}{|c|}{ Identitas } & \\
\hline & \multicolumn{2}{|r|}{ Mulai } & & \\
\hline \multirow{5}{*}{ Evaluasi 2} & \multicolumn{2}{|c|}{ Materi } & & \\
\hline & & Info & Suara & Print \\
\hline & \multicolumn{3}{|c|}{ Petunjuk Penggunaan Kuis } & \\
\hline & \multicolumn{4}{|c|}{ Keterangan Kuis } \\
\hline & & \multicolumn{2}{|c|}{ Lanjut } & \\
\hline \multirow{4}{*}{ Evaluasi 3} & \multicolumn{2}{|c|}{ Materi } & \multicolumn{2}{|r|}{ Waktu } \\
\hline & & Info & Suara & Print \\
\hline & \multicolumn{2}{|c|}{ Soal } & \multicolumn{2}{|c|}{ Gambar } \\
\hline & Menu & & & Lanjut \\
\hline \multirow[b]{3}{*}{ Materi 1} & \multicolumn{2}{|c|}{ Materi } & \multicolumn{2}{|c|}{ Pembahasan } \\
\hline & Sub Materi & Sub Mater & & Materi \\
\hline & \multicolumn{4}{|c|}{ Isi Materi } \\
\hline \multirow{4}{*}{ Materi 2} & \multicolumn{2}{|c|}{ Materi } & \multicolumn{2}{|c|}{ Pembahasan } \\
\hline & Sub Materi & Sub Materi & & Materi \\
\hline & Menu & & ahasan & \\
\hline & & & & $\Delta \sqrt{L}$ \\
\hline
\end{tabular}

Sebelum kuis diujicobakan, desain kuis pembelajaran terlebih dahulu melalui proses validasi oleh ahli materi dan ahli media. Saran yang didapatkan digunakan sebagai acuan perbaikan desain awal yang telah direncanakan. Setelah media selesai dikembangkan, selanjutnya dilakukan uji coba kepada responden uji coba yang telah ditentukan untuk melihat persepsi responden terhadap media pembelajaran yang dikembangkan. Pengambilan data persepsi responden terhadap kuis interaktif menggunakan instrumen tes yang terdiri dari 13 item dan diujikan kepada 33 responden. Tampilan media pembelajaran yang siap diujicobakan kepada responden disajikan pada Tabel 4.

Tabel 4. Tampilan kuis interaktif setelah revisi

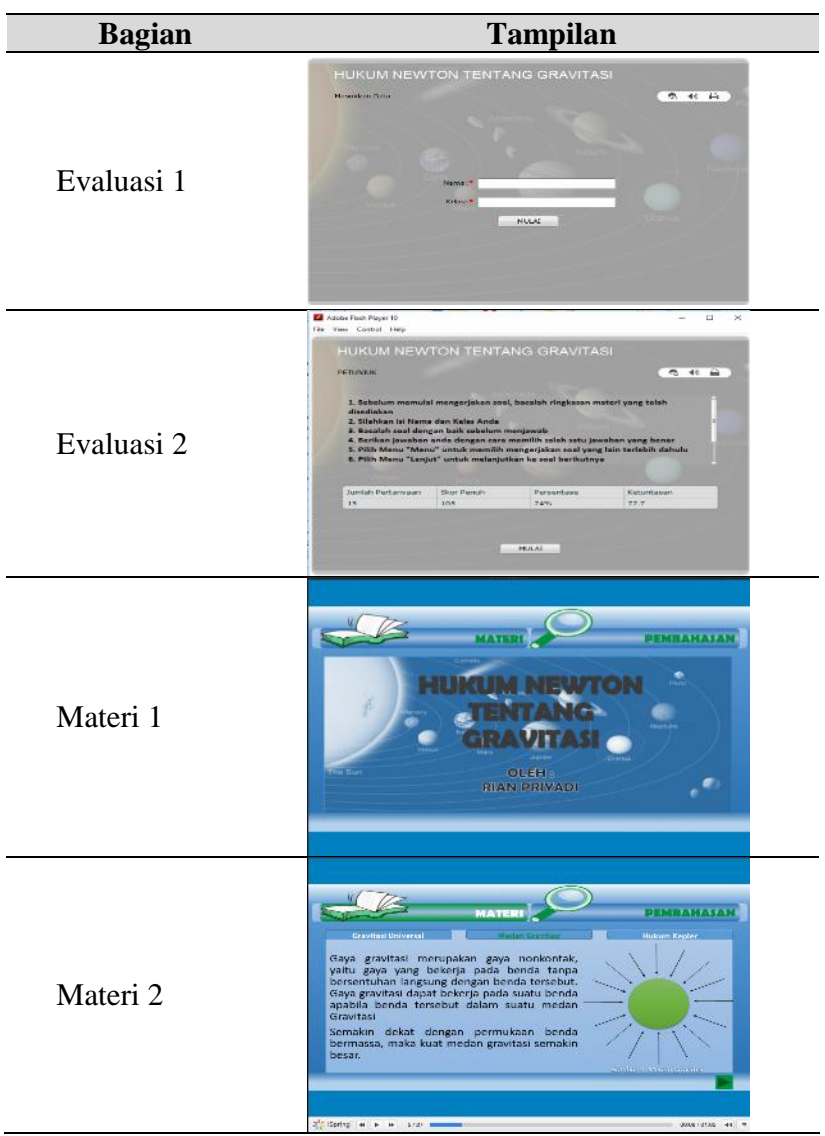

Hasil uji coba menunjukkan bahwa media pembelajaran berbasis teknologi yang dikembangkan mendapatkan respon baik serta bermanfaat bagi responden, hal ini ditunjukkan dari perolehan persentase rata-rata sebesar 79,7\% (Praktis) dengan rincian skor pada masing-masing aspek disajikan pada Tabel 5 .

Tabel 5. Peroleh skor uji coba responden

\begin{tabular}{lll}
\hline Aspek & Persentase & Kategori \\
\hline Efektifitas & $83,7 \%$ & Sangat Praktis \\
Motivasi belajar & $76,4 \%$ & Praktis \\
Aktivitas belajar & $72,7 \%$ & Praktis \\
\hline Rata-rata & $79,7 \%$ & Praktis \\
\hline
\end{tabular}

Media pembelajaran yang dikembangkan telah dilengkapi dengan evaluasi dan pembahasan pada setiap butir soal. Namun, penelitian ini masih terbatas pada tahapan develop sehingga belum diketahui efektifitas penggunaan media pembelajaran berbasis teknologi sebagai bahan ajar. Kepada peneliti lain disarankan agar melanjutkan penelitian pada tahapan disseminate dengan menggunakan media pembelajaran berbasis teknologi sebagai bahan ajar di kelas. Selain itu, disarankan juga untuk mengembangkan hal serupa pada materi yang lain agar dapat menambah fasilitas belajar siswa. 


\section{Kesimpulan}

Berdasarkan hasil analisis data, telah dihasilkan kuis pembelajaran berbasis teknologi pembelajaran fisika pada materi hukum gravitasi universal yang valid dan layak digunakan. Spesifikasi produk yang dikembangkan adalah media pembelajaran berbasis teknologi yang mudah dipergunakan oleh siswa karena dapat dijalankan dengan mudah dan dapat dipergunakan secara mandiri oleh siswa di luar sekolah.

Saran yang dapat diberikan pada penelitian ini adalah kepada peneliti lainnya untuk melakukan uji coba pemakaian untuk mengetahui efektifitas media pembelajaran yang telah dikembangkan. Selain itu, kepada peneliti lainnya untuk mengembangkan kuis interaktif pada materi lainnya agar tersedia bahan ajar yang cukup bagi responden dalam mempelajari konsep fisika.

\section{Kepustakaan}

[1] R. Priyadi, S. Kusairi, and N. Indrasari, "Desain dan Pengembangan Video Pembelajaran Gerak Parabola Sebagai Fasilitas Remediasi Siswa," J. Pendidik. Mat. dan Sains, vol. 6, no. 1 , pp. 20-28, 2018.

[2] N. Khoirudin, D. Wahyuningsih, and D. Teguh, "Pengembangan Media Pembelajaran dengan Menggunakan Aplikasi Mindjet Mindmanager 9 untuk Siswa SMA pada Pokok Bahasan Alat Optik," J. Pendidik. Fis., vol. 1, no. 1, pp. 1-10, 2013.

[3] I. M. Astra, "Aplikasi Mobile Learning Fisika dengan Menggunakan Adobe Flash sebagai Media Pembelajaran Pendukung," J. Pendidik. dan Kebud., vol. 18, no. 2, p. 174, Jun. 2012.

[4] I. D. Kurniawati and S.- Nita, "Media Pembelajaran Bebrbasis Multimedia Interaktif untuk Meningkatkan Pemahaman Konsep Mahasiswa," DOUBLECLICK J. Comput. Inf. Technol., vol. 1, no. 2, p. 68, Feb. 2018.

[5] A. Sadiman, Media Pendidikan. Jakarta: Raja Grafindo, 2014.

[6] A. Arsyad, Media Pembelajaran, Edisi Revisi. Jakarta: Raja Grafindo, 2014.

[7] E. Dale, Audio-visual Methods in Teaching. New York: Dryden Press, 1969.

[8] S. Tiagarajan, D. S. Sammel, and M. I. Semmel, Instructional Development for Training Teacher of Exceptional Children: A Sourcebook. Minneapolis, Minnesota: University of Minnesota, 1974.

[9] Sugiyono, Metode Penelitian Pendidikan: Pendekatan Kuantitatif, Kualitatif, dan R\&D. Bandung: Alfabeta, 2015.

[10] N. Sudjana and A. Rivai, Media Pengajaran. Bandung: CV Sinar Baru, 1990.

[11] L. M. Silberman, Active Learning: 101 Cara Peserta didik Belajar Aktif. Bandung: Nusa Media, 2013. 